\title{
AN OPTIMAL DIET IN PROMOTING NITROGEN GAIN IN NEPHROSIS ${ }^{1}$
}

\author{
By SHIH-HAO LIU AND HSIEN-I CHU \\ (From the Department of Medicine, Peiping Union Medical College, Peiping, China)
}

(Received for publication July 14, 1933) ${ }^{2}$

The present state of our knowledge of nephrosis leaves very little doubt that the level of plasma proteins is one of the important factors that control the fluid distribution between blood and tissues. According to the work of Moore and Van Slyke (1) the relations between plasma protein content and nephrotic edema are such that the critical point below which edema occurs is approximately 2.5 per cent albumin and 5.5 per cent total proteins. This has been found generally true both in pure nephrosis and in the nephrotic stage of chronic hemorrhagic nephritis. Similarly through a deficit in plasma proteins, edema may be brought about in dogs by plasmapheresis $(2,3)$ and occurs in man with malnutrition (4, $5,6,7)$. While the plasma protein deficit in plasmapheresis and nutritional edema can be easily explained, the cause of low plasma protein in nephrosis is more obscure. Epstein $(8,9)$, Kollert (10) and others attribute the low albumin content to direct loss of albumin in urine, while Peters, Bulger et al. (11) emphasize the importance of protein deprivation or starvation as an additional factor in the production of plasma protein deficit in nephrosis. Through lack of appetite or through misdirected management patients with this disease receive a diet containing proteins far short of their needs.

With a realization of the importance of a plasma protein deficit and its contributing causes, attempts have been made to raise plasma proteins by dietary means. Epstein (8) was the first to advocate a high protein diet in the treatment of nephrosis and clinical observation convinced him of the efficacy of the treatment. The use of a high protein diet was supported by the work of

1 A preliminary report of this work appeared in Proc. Soc. Exper. Biol. and Med., 1933, 30, 986.

2 This paper as revised by the authors was lost in transit to the Journal about September 1, 1933. Following inquiry from the authors on January 21, 1935, the loss was discovered. A copy of the manuscript was sent to the Journal and was received January 25, 1935.
MacLean (12) and Worley (13). Others, however, are less favorably impressed by Epstein's diets. Linder, Lundsgaard and Van Slyke (14) are of the opinion that diets in nephrosis should contain an adequate but not an excessive amount of protein. Peters and his colleagues (11) have defined the dietary requirements for nephritis more accurately. They conclude that besides enough protein to cover the nitrogen catabolism and that lost as albumin in urine, the patients should be given an additional amount of protein to repair the previous nitrogen wastage and, if possible, the plasma protein deficit. By the administration of large amounts of carbohydrate and fat it has been possible to reduce the protein catabolism to 0.5 to 0.7 gram per $\mathrm{kgm}$. of body weight, per day.

The work reported in this paper was undertaken to discover a diet so constituted in caloric and protein intake that it would insure a maximum gain in nitrogen without necessarily imposing on the appetite of the patients. The possible effects of varying proportions of animal and vegetable proteins were also taken into consideration. Such a study requires rigid dietary control for a long period of time and may not be applicable to many nephrotic patients in the active stage when they have precarious appetites. Consequently the number of patients suitable for such a study is limited. We have two cases in which sufficient data have been obtained to permit us to draw certain conclusions in regard to the composition of what may be called an optimal diet for nephrosis.

\section{EXPERIMENTAL SUBJECTS}

Case 1. J. S. Y., a Chinese boy of 10 was admitted July 1, 1928, for edema of the face, extremities and genitalia which had begun 3 weeks prior to admission. There was no history of febrile disease preceding the appearance of edema, nor 'was the present illness accompanied by any constitutional symptoms. He presented general anasarca, a temperature of $39.6^{\circ} \mathrm{C}$., pulse 140 , respiration 34 , blood pressure $100 / 66$. No foci of infection were evident in nose, pharynx, teeth, or ears. The ocular fundi were normal. There was no dullness over the lungs, but 
râles were heard everywhere. The heart was not enlarged and no murmurs were heard. The abdomen was distended and there was free fluid in the peritoneal cavity. The urine contained ++ albumin, no sugar; in the sediment were found many white blood cells, red blood cells and hyaline and granular casts; the guaiac test was positive. The phenolsulphonphthalein excretion was 55 per cent in two hours. There was no anemia. The leukocyte count varied between 7000 and 12,000. Blood chemical findings were as follows: nonprotein nitrogen $35 \mathrm{mgm}$., uric acid $4.7 \mathrm{mgm}$., creatinine $1.5 \mathrm{mgm}$., and cholesterol $533 \mathrm{mgm}$., per $100 \mathrm{cc}$; plasma albumin 3.3 per cent and total proteins 5.2 per cent; carbon dioxide capacity, 54 volumes per cent. The basal metabolic rate was -9.4 per cent.

There was on admission acute bronchitis which subsided promptly with return to normal of temperature and pulse rate. Edema decreased rapidly following catharsis with magnesium sulphate. After this, edema recurred at intervals. In December 1928, at the height of edema, a right maxillary sinusitis was discovered. Puncture secured thick pus, culture of which showed Streptococcus hemolyticus, Staphylococcus aureus and B. coli. After repeated irrigations the sinusitis cleared up and edema disappeared. He gained $3 \mathrm{kgm}$. of body weight, without edema, in the next three months. The plasma proteins rose slightly, the albumin to 4.0 per cent and the total proteins to 5.9 per cent. Cholesterol decreased to 101 mgm. per cent. The urine, however, still contained albumin and a few red blood cells. The patient was discharged in good condition in April of 1929.

For the remainder of the year 1929, he stayed at home and did fairly well. But in the following year, 1930, he had to be readmitted to the hospital five times because of recurrences of edema. Each recurrence was apparently associated with some acute respiratory infection, such as tonsillitis, bronchitis and pharyngitis. After each admission edema subsided promptly, although slight pitting over the ankles persisted. Tonsillectomy was done in May, during the fourth admission, with practically no reaction. During the year plasma albumin varied between 1 and 2 per cent and total proteins between 3 and 5 per cent. Usually marked edema was accompanied by lower plasma proteins. Blood cholesterol varied between 300 and $500 \mathrm{mgm}$. per cent.

On the sixth admission the patient stayed in the hospital for approximately six months (from December 27, 1930 , to June 15, 1931). During this period, after the initial rapid loss of edema, his condition remained almost stationary. Slight pitting edema was always present over the ankles. Plasma albumin fluctuated around 2 per cent, total proteins around 4.5 per cent, and blood cholesterol around $300 \mathrm{mgm}$. per cent. Albuminuria was constantly present to the extent of 1 to 4 grams per day. Sediment count according to the technique of Addis showed 280,000 casts, $1,700,000$ red blood cells, and 11,000,000 leukocytes and epithelial cells per 12 hours. During the months of January to March, he served as an experimental subject for the study of the effects on water balance of acids and alkalis. During March and April the effect of thyroid medication was studied. These studies will be reported separately.

In September 1931 he returned for his seventh admission at our request. He had done well in the summer and on admission there was only slight edema over both tibiae. Plasma proteins were approximately at the same level as on preceding admission, although blood cholesterol was only $150 \mathrm{mgm}$. per cent and stayed at this level. The urine showed a faint trace of albumin. A sediment count revealed 56,000 casts, 4,500 erythrocytes, and 600,000 white blood cells in 12 hours. Soon after admission he developed a febrile illness which lasted approximately three weeks. This proved to be paratyphoid A fever. He did not suffer much subjectively, although he lost approximately $2 \mathrm{kgm}$. in body weight and the plasma albumin came down to 1.5 per cent and total proteins to 3.7 per cent at the height of the illness. Of great interest was the complete disappearance of albuminuria after he recovered from the infection. A sediment count revealed approximately 2000 casts, 200 red blood cells, and 13,000 leukocytes, figures well within normal limits. He was then entirely free from edema and steadily put on weight. The plasma albumin rose rapidly to approximately 4 per cent and total proteins to 6 per cent, at which levels they remained throughout the remaining period of observation. He was, in short, considered a normal individual. His otherwise uneventful course in the hospital was interrupted by a mild attack of chickenpox in April and of pityriasis rosea in May 1932. He stayed in the hospital for approximately 9 months. From October 16, 1931, to April 24, 1932, he was studied from the standpoint of nitrogen balance on diets containing different amounts of calories and protein (see Table I) and different percentages of animal and vegetable proteins. From April 25 to June 11, he was again observed for the effect of thyroid medication so as to compare the results with those of the earlier period in which he was still in the nephrotic state.

Case 2. F. H. T., a farm laborer of 35 , was admitted June 8,1931 , for ulceration of the skin of 10 months' duration and general anasarca of 4 weeks' duration. He was discharged improved June 13, 1932. A year prior to admission the patient had a venereal exposure followed by urethral discharge, a penile sore, and a generalized reddish papular skin eruption. These cleared up promptly. Approximately 8 months prior to admission, he noticed that many of the faded papules over the extremities, buttocks, face and scalp began to spread and become ulcerated. Various local applications were used without result. Four weeks prior to admission, edema of the lower extremities was noted and very soon his external genitalia, face, and upper extremities became involved. Scanty urination and loss of strength were accompanying symptoms. There was no fever and the appetite remained good.

Physical examination revealed a moderately sick and slightly emaciated man with temperature $37.2^{\circ} \mathrm{C}$., pulse 104, respirations 20 , blood pressure $90 / 70$. Over the 
right thigh, left popliteal and elbow regions, buttocks, face and scalp, there were large areas of superficial annular ulcerative lesions with atrophic scars in the center. The lower extremities, external genitalia and lower lumbar region were markedly edematous, while the forearms, backs of hands and abdominal wall were slightly so. He had advanced trachoma with ectropion of the left lower eyelid. The pupillary reactions and ocular fundi were normal. The epitrochlear and inguinal lymph nodes were palpable. The lungs were clear, although the bases were high. The heart showed no abnormality. The abdomen was distended, with bulging of the flanks, a fluid wave and shifting dullness.

Laboratory examinations. The urine contained +++ albumin with many hyaline and granular casts and leukocytes. No red blood cells were noticed on repeated examination. A smear of the sediment showed gramnegative diplococci, both extra- and intracellular. The phenolsulphonphthalein excretion was 15 per cent in 2 hours, the urea clearance test, 35 per cent of normal. A sediment count (Addis) showed white blood and epithelial cells to be 1.4 , red blood cells 0.207 and casts 0.726 million per 12 hours. Blood counts revealed slight anemia with a normal number of white blood cells. Blood Wassermann and Kahn tests were both strongly positive. The blood nonprotein nitrogen was $65 \mathrm{mgm}$. per cent, cholesterol $208 \mathrm{mgm}$. per cent, plasma $\mathrm{CO}_{2}$ capacity 45.8 volumes per cent, plasma albumin 1.11 per cent and total proteins 3.15 per cent. Stools contained trichomonas and ova of ascaris and hookworm. The basal metabolic rate was -4.3 per cent.

The main diagnoses in this case were nephrosis and syphilis with skin manifestations. Chronic gonococcal urethritis, ankylostomiasis, ascariasis and trichomoniasis were incidental conditions.

Anti-syphilitic treatment was commenced shortly after admission and the skin lesions healed completely after the third injection of neoarsphenamine. The injections were continued at weekly intervals until he had received 22 injections of neoarsphenamine and 14 of sodium potassium bismuth tartrate. His blood Wassermann reaction became negative on October 7, 1932, 16 months after the commencement of treatment.

No special treatment was instituted for his renal condition except a diet that contained 120 grams of proteins and 2200 to 3200 calories with limited amounts of fluid and salt. His edema remained stationary until about 3 weeks after admission when it began to subside. Within the next 6 to 7 weeks, his body weight decreased from 57.6 to $43.4 \mathrm{kgm}$., a decrease of $14 \mathrm{kgm}$., resulting in the disappearance of gross edema. Slight pitting edema over the tibiae could still be demonstrated for the next 5 months, after which he became entirely free from edema. He steadily put on flesh so that a maximum weight of $60 \mathrm{kgm}$. was reached 9 months after gross edema had disappeared. During the period of rapid discharge of edema his plasma albumin was 1.5 per cent and total proteins 3.1 per cent. These gradually increased so that his plasma albumin became 3.5 per cent and total proteins 6.0 per cent 7 months after admission, when edema had entirely disappeared. After that the plasma proteins stayed at these levels throughout the period of observation. Albuminuria also improved, though slowly. It averaged 12 grams per day on admission and decreased to $0.5 \mathrm{gram}$ per day on discharge. Occasional hyaline casts were still present on discharge. The phenolsulphonphthalein excretion was 75 per cent on discharge, the blood pressure 110/60.

From September 30, 1931, to April 24, 1932, the patient was on a rigidly controlled regime for the study of nitrogen balance in relation to the intake of protein and calories. From April 25 to June 11, 1932, thyroid was administered to ascertain its effect on the nitrogen and respiratory metabolism during the symptom-free period of nephrosis.

A follow-up examination on October 7, 1932, showed the patient to be in good nutrition without any evidence of edema. The urine contained a trace of albumin, occasional hyaline casts and a few leukocytes. The urea clearance test was 92 per cent of normal, the blood nonprotein nitrogen $47 \mathrm{mgm}$. per cent, plasma albumin 3.72 per cent and total proteins 5.91 per cent.

\section{PROCEDURE}

The patients had been placed in the Metabolism Ward for some time before metabolism studies were commenced. Diets were accurately prepared and served, and stools and urine completely collected.

Diets. The food values were taken from the compilations of $\mathrm{Wu}(15)$, based on analysis of local articles of food. Tables I and II give the composition of various diets taken by the patients. Each diet was used for two to three periods of 4 days each, but occasionally observations on a given diet were extended to four or five periods. As indicated in the tables, the general plan was to study the effect of three variables in the diets, namely, caloric intake, protein intake, and variations in the proportion of animal and vegetable proteins. When the effect of one variable was studied, the other two were held constant. From Table $I$ it can be seen that Periods 5 to 21 were devoted to the study of the effect of variations in caloric intake from 1500 to 2590 , with an approximately constant protein intake of 50 grams, of which 50 per cent were of animal origin. Periods 22 to 32 were used to study the effect of varying the protein intake from 50 to 125 grams, with a constant caloric intake of 2310 and 50 per cent of animal protein. Periods 1 to 4 and 33 to 47 are to be considered together. During these the effect of varying the percentage of animal and 
TABLE I

Case 1. Composition of diets

\begin{tabular}{|c|c|c|c|c|c|c|c|c|c|c|c|}
\hline $\begin{array}{c}\text { Period } \\
\text { number }\end{array}$ & Date & $\begin{array}{l}\text { Pro- } \\
\text { tein }\end{array}$ & 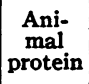 & Fat & $\begin{array}{l}\text { Carbo- } \\
\text { hydrate }\end{array}$ & Calories & Salt & $\begin{array}{c}\text { Average } \\
\text { body } \\
\text { weight }\end{array}$ & $\begin{array}{c}\text { Protein } \\
\text { per } \\
\text { kgm. }\end{array}$ & $\begin{array}{c}\text { Calories } \\
\text { per } \\
\text { kgm. }\end{array}$ & $\begin{array}{c}\text { Calories } \\
\text { from } \\
\text { protein }\end{array}$ \\
\hline $\begin{array}{l}1-2 \\
3-4 \\
5-7 \\
8-9 \\
10-11 \\
12-13 \\
14-15 \\
16-17 \\
18-19 \\
20-21 \\
22-23 \\
24-26 \\
27-29 \\
30-32 \\
33-35 \\
36-38 \\
39-42 \\
43-45 \\
46-47\end{array}$ & $\begin{array}{l}\text { Oct. 16-23 } \\
\text { Oct. 24-Nov. } 4 \\
\text { Nov. 5-16 } \\
\text { Nov. 17-24 } \\
\text { Nov. 25-Dec. } 2 \\
\text { Dec. 3-10 } \\
\text { Dec. 11-18 } \\
\text { Dec. 19-26 } \\
\text { Dec. 27-Jan. } 3 \\
\text { Jan. 4-11 } \\
\text { Jan. 12-19 } \\
\text { Jan. 20-31 } \\
\text { Feb. 1-12 } \\
\text { Feb. 13-24 } \\
\text { Feb. 25-Mar. } 7 \\
\text { Mar. 8-19 } \\
\text { Mar. 20-Apr. } 4 \\
\text { Apr. 5-16 } \\
\text { Apr. 17-24 }\end{array}$ & $\begin{array}{r}\text { grams } \\
24.6 \\
25.2 \\
50.2 \\
50.1 \\
50.3 \\
50.2 \\
50.0 \\
50.0 \\
50.0 \\
50.0 \\
50.1 \\
74.9 \\
100.0 \\
125.3 \\
74.8 \\
75.2 \\
74.8 \\
75.5 \\
75.1\end{array}$ & $\begin{array}{c}\text { per cent } \\
0 \\
92 \\
50 \\
50 \\
50 \\
50 \\
50 \\
50 \\
50 \\
50 \\
50 \\
50 \\
50 \\
50 \\
50 \\
25 \\
0 \\
99 \\
75\end{array}$ & $\begin{array}{r}\text { grams } \\
50 \\
50 \\
50 \\
70 \\
90 \\
110 \\
90 \\
70 \\
50 \\
40 \\
90 \\
90 \\
90 \\
90 \\
90 \\
90 \\
90 \\
90 \\
90\end{array}$ & $\begin{array}{l}\text { grams } \\
298 \\
300 \\
275 \\
300 \\
325 \\
350 \\
325 \\
300 \\
275 \\
235 \\
325 \\
300 \\
275 \\
250 \\
300 \\
300 \\
300 \\
300 \\
300\end{array}$ & $\begin{array}{l}1741 \\
1750 \\
1751 \\
2030 \\
2311 \\
2591 \\
2310 \\
2030 \\
1750 \\
1500 \\
2310 \\
2310 \\
2310 \\
2311 \\
2309 \\
2311 \\
2309 \\
2312 \\
2310\end{array}$ & $\begin{array}{c}\text { grams } \\
6 \\
6 \\
6 \\
6 \\
6 \\
6 \\
6 \\
6 \\
6 \\
6 \\
6 \\
6 \\
6 \\
6 \\
6 \\
6 \\
6 \\
6 \\
6\end{array}$ & $\begin{array}{l}\mathrm{kgm} . \\
25.8 \\
26.0 \\
27.1 \\
28.0 \\
28.5 \\
29.4 \\
29.7 \\
29.7 \\
29.7 \\
29.4 \\
29.6 \\
30.1 \\
30.5 \\
30.9 \\
31.1 \\
31.5 \\
31.5 \\
32.0 \\
32.0\end{array}$ & $\begin{array}{l}\text { grams } \\
0.95 \\
0.97 \\
1.85 \\
1.79 \\
1.76 \\
1.71 \\
1.68 \\
1.68 \\
1.68 \\
1.70 \\
1.69 \\
2.49 \\
3.28 \\
4.05 \\
2.41 \\
2.41 \\
2.38 \\
2.36 \\
2.35\end{array}$ & $\begin{array}{l}67 \\
67 \\
65 \\
73 \\
81 \\
88 \\
78 \\
68 \\
59 \\
51 \\
78 \\
77 \\
76 \\
75 \\
74 \\
73 \\
73 \\
72 \\
72\end{array}$ & $\begin{array}{r}\text { per cent } \\
5.6 \\
5.8 \\
11.5 \\
9.9 \\
8.7 \\
7.7 \\
8.7 \\
9.9 \\
11.5 \\
13.3 \\
8.7 \\
13.0 \\
17.3 \\
21.6 \\
13.0 \\
13.0 \\
13.0 \\
13.0 \\
13.0\end{array}$ \\
\hline
\end{tabular}

vegetable protein was studied. In Periods 1 to 4 protein was kept at approximately 25 grams and calories at 1750 , while in the last 15 periods these values were 75 grams and 2310 calories respectively.

A similar procedure was followed in Case 2 (Table II). The first 16 periods were used to observe the effect of varying caloric intake from 1800 to 3770 , with a fairly constant protein intake of 75 grams, and the percentage of animal protein at 44 to 65 per cent. Periods 17 to 19 were " nitrogen free" periods for the purpose of studying the endogenous nitrogen metabolism. These were followed by two periods of fairly liberal protein intake, merely to fill up the depleted nitrogen stores somewhat before commencing the next series of studies. During the next 14 periods (22 to 35 ) the caloric intake was held at 3260 with

TABLE II

Case 2. Composition of diets

\begin{tabular}{|c|c|c|c|c|c|c|c|c|c|c|c|}
\hline $\begin{array}{l}\text { Period } \\
\text { number }\end{array}$ & Date & $\begin{array}{l}\text { Pro- } \\
\text { tein }\end{array}$ & $\underset{\text { mal }}{\underset{\text { malein }}{\text { protein }}}$ & Fat & $\begin{array}{l}\text { Carbo- } \\
\text { hydrate }\end{array}$ & Calories & Salt & $\begin{array}{c}\text { Average } \\
\text { body } \\
\text { weight }\end{array}$ & $\begin{array}{c}\text { Protein } \\
\text { per } \\
\text { kgm. }\end{array}$ & $\begin{array}{c}\text { Calories } \\
\text { per } \\
\text { kgm. }\end{array}$ & $\begin{array}{c}\text { Calories } \\
\text { from } \\
\text { protein }\end{array}$ \\
\hline $\begin{array}{c}1-2 \\
3-4 \\
5-6 \\
7-8 \\
9-10 \\
11-12 \\
13-14 \\
15-16 \\
17-19 \\
20-21 \\
22-23 \\
24-25 \\
26-27 \\
28-30 \\
31-33 \\
34-35 \\
36-39 \\
40-42 \\
43-47 \\
48-50 \\
51-53\end{array}$ & $\begin{array}{l}\text { Sept. } 30-\text { Oct. } 7 \\
\text { Oct. } 8-15 \\
\text { Oct. } 16-23 \\
\text { Oct. } 24-31 \\
\text { Nov. } 1-8 \\
\text { Nov. } 9-16 \\
\text { Nov. } 17-24 \\
\text { Nov. } 25-\text { Dec. } 2 \\
\text { Dec. } 3-14 \\
\text { Dec. } 15-22 \\
\text { Dec. } 23-30 \\
\text { Dec. } 31-J a n .7 \\
\text { Jan. } 8-15 \\
\text { Jan. } 16-27 \\
\text { Jan. } 28-F e b .8 \\
\text { Feb. } 9-16 \\
\text { Feb. } 17-M a r .3 \\
\text { Mar. } 4-15 \\
\text { Mar. 16-Apr. } 4 \\
\text { Apr. 5-16 } \\
\text { Apr. 17-28 }\end{array}$ & $\begin{array}{c}\text { grams } \\
75 \\
75 \\
75 \\
75 \\
75 \\
75 \\
76 \\
75 \\
2 \\
75 \\
75 \\
50 \\
100 \\
125 \\
150 \\
175 \\
100 \\
100 \\
100 \\
100 \\
100\end{array}$ & $\begin{array}{c}\text { per cent } \\
65 \\
42 \\
45 \\
44 \\
44 \\
46 \\
52 \\
62 \\
0 \\
40 \\
50 \\
50 \\
50 \\
50 \\
50 \\
50 \\
50 \\
25 \\
0 \\
98 \\
75\end{array}$ & $\begin{array}{c}\text { grams } \\
60 \\
100 \\
120 \\
150 \\
190 \\
150 \\
120 \\
100 \\
105 \\
100 \\
150 \\
150 \\
140 \\
140 \\
130 \\
125 \\
140 \\
140 \\
140 \\
140 \\
140\end{array}$ & 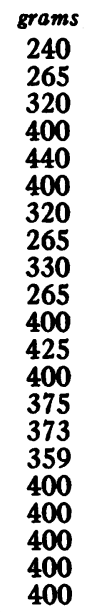 & $\begin{array}{l}1800 \\
2260 \\
2660 \\
3250 \\
3770 \\
3250 \\
2664 \\
2260 \\
2273 \\
2260 \\
3260 \\
3260 \\
3260 \\
3260 \\
3260 \\
3261 \\
3260 \\
3260 \\
3260 \\
3260 \\
3260\end{array}$ & $\begin{array}{c}\text { grams } \\
\mathbf{3} \\
\mathbf{5} \\
\mathbf{5} \\
\mathbf{5} \\
\mathbf{5} \\
\mathbf{5} \\
\mathbf{5} \\
\mathbf{5} \\
\mathbf{5} \\
\mathbf{5} \\
\mathbf{5} \\
\mathbf{5} \\
\mathbf{5} \\
\mathbf{5} \\
\mathbf{5} \\
\mathbf{5} \\
\mathbf{5} \\
\mathbf{5} \\
\mathbf{5} \\
\mathbf{5} \\
\mathbf{5}\end{array}$ & $\begin{array}{l}\text { kgm. } \\
\mathbf{5 1 . 1} \\
\mathbf{5 0 . 9} \\
51.4 \\
52.3 \\
53.0 \\
54.0 \\
53.7 \\
\mathbf{5 3 . 4} \\
\mathbf{5 2 . 5} \\
\mathbf{5 1 . 8} \\
\mathbf{5 3 . 0} \\
\mathbf{5 3 . 7} \\
\mathbf{5 4 . 7} \\
\mathbf{5 5 . 6} \\
\mathbf{5 6 . 8} \\
\mathbf{5 7 . 7} \\
\mathbf{5 8 . 5} \\
\mathbf{5 9 . 3} \\
\mathbf{5 9 . 7} \\
\mathbf{5 9 . 8} \\
\mathbf{5 9 . 8}\end{array}$ & $\begin{array}{l}\text { grams } \\
1.47 \\
1.47 \\
1.46 \\
1.43 \\
1.42 \\
1.39 \\
1.42 \\
1.41 \\
0.04 \\
1.45 \\
1.42 \\
0.93 \\
1.82 \\
2.25 \\
2.64 \\
3.03 \\
1.71 \\
1.69\end{array}$ & $\begin{array}{l}35 \\
44 \\
52 \\
62 \\
71 \\
\mathbf{6 0} \\
\mathbf{5 0} \\
\mathbf{4 2} \\
\mathbf{4 3} \\
\mathbf{4 4} \\
\mathbf{6 1} \\
\mathbf{6 1} \\
\mathbf{6 0} \\
\mathbf{5 9} \\
\mathbf{5 7} \\
\mathbf{5 6} \\
\mathbf{5 6} \\
\mathbf{5 5} \\
\mathbf{5 5} \\
\mathbf{5 5} \\
\mathbf{5 5}\end{array}$ & $\begin{array}{c}\text { per cent } \\
16.7 \\
13.3 \\
11.3 \\
9.2 \\
8.0 \\
9.2 \\
11.4 \\
13.3 \\
0.4 \\
13.3 \\
9.2 \\
6.1 \\
12.2 \\
15.3 \\
18.3 \\
21.4 \\
12.3 \\
12.3 \\
12.3 \\
12.3 \\
12.3\end{array}$ \\
\hline
\end{tabular}


equal quantities of animal and vegetable protein, while the protein intake varied from 50 to 175 grams. In the last 18 periods (36 to 53 ), both the caloric and protein intake remained constant at 3260 and 100 grams respectively, while the proportion of animal protein was subjected to change from 0 to 98 per cent.

Collection of urine and stools. These were carried out as described in a previous study of nitrogen balance in nutritional edema (7).

Analytical methods. Urine nitrogen was determined on 24-hour collections by a modified Folin and Wright method (16). Proteins were separated from albumin-containing urine by adding an equal volume of 10 per cent trichloracetic acid, and an aliquot of the filtrate was taken for nonprotein nitrogen determination. Another untreated portion of urine was used for total nitrogen determination. The difference between the two determinations was taken to represent protein nitrogen. For stool nitrogen about 0.5 gram of dried stool, weighed on a chainomatic balance, was digested with $15 \mathrm{cc}$. of concentrated sulphuric acid, 6 cc. of 10 per cent ferric chloride, 10 drops of phosphoric acid and 5 drops of 5 per cent copper sulphate. Blood specimens were taken before breakfast with as little stasis as possible. Plasma proteins were separated by the method of Howe (17), and the albumin and globulin fractions de- termined by the gasometric technique of Van Slyke (18).

\section{OBSERVATIONS AND COMMENTS}

\section{Effect of caloric intake}

At a certain level of protein intake and with a given state of nutrition, on account of the proteinsparing action of carbohydrates and fat, the extent of positive nitrogen balance depends on the caloric intake. This is well illustrated in Case 2 (Table IV and Figure 2). This patient, while on a protein intake of 75 grams lost nitrogen on 1800 calories, or 35 calories per kgm., but gained nitrogen immediately when the caloric intake was increased to 2260 , or 44 calories per kgm. Successive caloric additions increased the nitrogen retention until it reached a maximum of 3.44 grams daily at 3250 calories, or 62 calories per $\mathrm{kgm}$. Further increase in caloric intake to 3770 , however, did not improve the nitrogen balance. On decreasing the caloric intake, the positive nitrogen balance became progressively less.

In the first patient (Table III and Figure 1) the extent of positive nitrogen balance on 50 grams of protein was not significantly altered by successive additions of calories from 1750 to 2590 , or from 65 to 88 calories per kgm. However, when the caloric intake was decreased from

TABLE III

Case 1. Effect of caloric intake.

Protein 50 grams. Animal protein 50 per cent

\begin{tabular}{|c|c|c|c|c|c|c|c|c|c|c|c|}
\hline \multirow{2}{*}{$\begin{array}{l}\text { Period } \\
\text { number }\end{array}$} & \multirow{2}{*}{ Calories } & \multicolumn{6}{|c|}{ Average daily nitrogen metabolism } & \multirow{2}{*}{$\begin{array}{c}\text { Body } \\
\text { weight } \\
\text { change }\end{array}$} & \multicolumn{3}{|c|}{ Plasma } \\
\hline & & Intake & Urine & Stool & Total & Balance & Average & & $\begin{array}{l}\text { Nonprotein } \\
\text { nitrogen }\end{array}$ & Albumin & $\begin{array}{c}\text { Total } \\
\text { protein }\end{array}$ \\
\hline & & grams & grams & grams & grams & grams & grams & kgm. & $\begin{array}{l}\text { mgm. per } \\
100 \text { cc. }\end{array}$ & $\begin{array}{c}\text { grams per } \\
100 \text { cc. }\end{array}$ & $\begin{array}{l}\text { grams per } \\
100 \text { cc. }\end{array}$ \\
\hline $\begin{array}{r}5 \\
6 \\
7 \\
8 \\
9 \\
10 \\
11 \\
12 \\
13 \\
14 \\
15 \\
16 \\
17 \\
18 \\
19 \\
20 \\
21\end{array}$ & $\begin{array}{l}1751 \\
1751 \\
1751 \\
2030 \\
2030 \\
2311 \\
2311 \\
2591 \\
2591 \\
2310 \\
2310 \\
2030 \\
2030 \\
1750 \\
1750 \\
1500 \\
1500\end{array}$ & $\begin{array}{l}8.00 \\
8.00 \\
8.00 \\
8.00 \\
8.00 \\
8.00 \\
8.00 \\
8.00 \\
7.96 \\
8.00 \\
8.00 \\
8.00 \\
8.00 \\
8.00 \\
8.00 \\
8.00 \\
8.00\end{array}$ & $\begin{array}{l}3.88 \\
4.33 \\
4.09 \\
4.14 \\
4.31 \\
4.51 \\
4.46 \\
4.38 \\
4.58 \\
5.72 \\
6.19 \\
6.18 \\
6.47 \\
6.60 \\
6.09 \\
7.23 \\
6.85\end{array}$ & $\begin{array}{l}0.86 \\
1.26 \\
1.23 \\
0.81 \\
0.82 \\
0.94 \\
1.44 \\
1.08 \\
1.15 \\
1.27 \\
1.18 \\
1.46 \\
1.05 \\
1.30 \\
1.21 \\
1.01 \\
0.94\end{array}$ & $\begin{array}{l}4.74 \\
5.59 \\
5.32 \\
4.95 \\
5.13 \\
5.45 \\
5.90 \\
5.46 \\
5.73 \\
6.99 \\
7.37 \\
7.64 \\
7.52 \\
7.90 \\
7.30 \\
8.24 \\
7.79\end{array}$ & $\begin{array}{r}+3.26 \\
+2.41 \\
+2.68 \\
+3.05 \\
+2.87 \\
+2.55 \\
+2.10 \\
+2.54 \\
+2.23 \\
+1.01 \\
+0.63 \\
+0.36 \\
+0.48 \\
+0.10 \\
+0.70 \\
-0.24 \\
+0.21\end{array}$ & $\begin{array}{l}+2.78 \\
+2.96 \\
+2.32 \\
+2.38 \\
+0.82 \\
+0.42 \\
+0.40 \\
-0.02\end{array}$ & $\begin{array}{l}+0.26 \\
+0.83 \\
+0.31 \\
+0.27 \\
+0.12 \\
+0.50 \\
+0.48 \\
+0.32 \\
+0.38 \\
+0.31 \\
+0.34 \\
-0.22 \\
+0.12 \\
-0.16 \\
-0.13 \\
-0.01 \\
-0.22\end{array}$ & $\begin{array}{l}17 \\
13 \\
20 \\
21 \\
19 \\
17 \\
19 \\
19 \\
22 \\
22 \\
20 \\
22 \\
19 \\
21\end{array}$ & $\begin{array}{l}4.15 \\
3.55 \\
3.39 \\
3.81 \\
3.90 \\
3.95 \\
3.33 \\
3.45 \\
3.57 \\
3.70 \\
3.81 \\
3.64 \\
3.80 \\
3.59 \\
3.65 \\
3.86 \\
3.76\end{array}$ & $\begin{array}{l}\mathbf{6 . 4 6} \\
\mathbf{5 . 4 4} \\
\mathbf{5 . 6 6} \\
\mathbf{5 . 9 8} \\
\mathbf{5 . 7 3} \\
\mathbf{5 . 8 1} \\
\mathbf{5 . 6 5} \\
\mathbf{5 . 9 3} \\
\mathbf{6 . 4 0} \\
\mathbf{6 . 0 6} \\
\mathbf{6 . 1 6} \\
\mathbf{6 . 0 8} \\
\mathbf{6 . 1 7} \\
\mathbf{5 . 7 6} \\
\mathbf{5 . 7 4} \\
\mathbf{6 . 0 8} \\
\mathbf{5 . 8 2}\end{array}$ \\
\hline
\end{tabular}


2590 , he retained progressively less nitrogen so that when he was on 1500 calories, or 51 calories per kgm., he could hardly maintain nitrogen balance. As noted in the case report, this patient was convalescing from paratyphoid A fever be- fore the studies were started. Consequently, his nitrogen stores were probably so impoverished that, from a diet of 50 grams of protein and 1750 calories, he was able to retain a relatively large amount of nitrogen. This amount was not in-

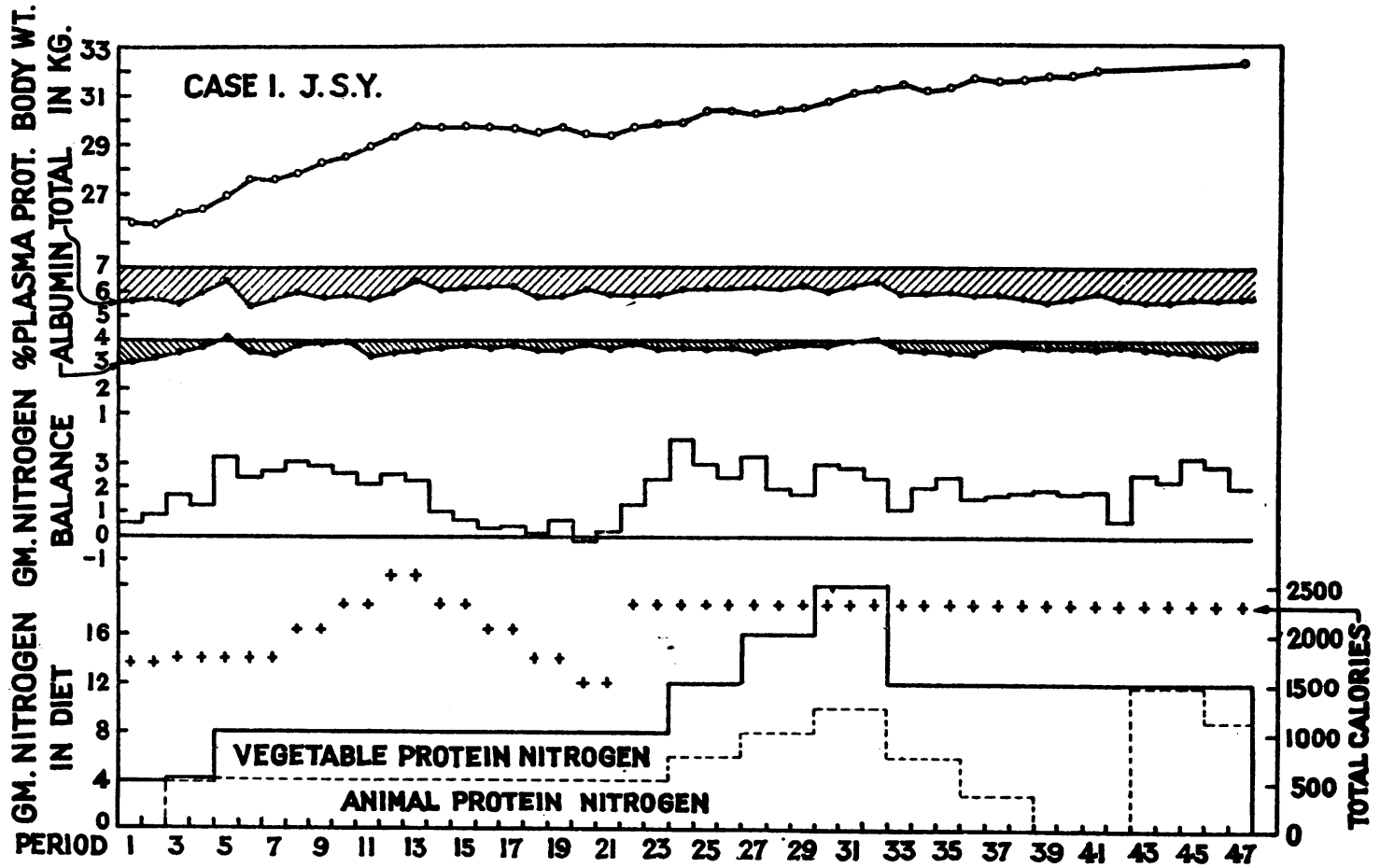

Fig. 1. Case 1. Nitrogen Balance, Plasma Proteins, and Body Weight on Diets with Varying Total Calories, Protein Intake, and Proportion of Animal and Vegetable Protein.

TABLE IV

Case 2. Effect of caloric intake

Protein 75 grams. Animal protein 44 to 65 per cent

\begin{tabular}{|c|c|c|c|c|c|c|c|c|c|c|c|c|}
\hline \multirow[b]{2}{*}{$\begin{array}{l}\text { Period } \\
\text { number }\end{array}$} & \multirow[b]{2}{*}{ Calories } & \multicolumn{7}{|c|}{ Average daily nitrogen metabolism } & \multirow{2}{*}{$\begin{array}{c}\text { Body } \\
\text { weight } \\
\text { change }\end{array}$} & \multicolumn{3}{|c|}{ Plasma } \\
\hline & & Intake & Urine & Stool & $\begin{array}{l}\text { Total } \\
\text { output }\end{array}$ & Balance & $\begin{array}{l}\text { Average } \\
\text { balance }\end{array}$ & $\begin{array}{c}\text { Urine } \\
\text { protein } \\
\text { nitrogen }\end{array}$ & & $\begin{array}{l}\text { Nonprotein } \\
\text { nitrogen }\end{array}$ & Albumin & $\begin{array}{c}\text { Total } \\
\text { protein }\end{array}$ \\
\hline & & grams & grams & grams & grams & grams & grams & grams & kgm. & $\begin{array}{l}\text { mgm. per } \\
100 \text { cc. }\end{array}$ & $\begin{array}{c}\text { grams per } \\
100 \text { cc. }\end{array}$ & $\begin{array}{l}\text { grams per } \\
100 \text { cc. }\end{array}$ \\
\hline $\begin{array}{r}1 \\
2 \\
3 \\
4 \\
5 \\
6 \\
7 \\
8 \\
9 \\
10 \\
11 \\
12 \\
13 \\
14 \\
15 \\
16\end{array}$ & $\begin{array}{l}1800 \\
1800 \\
2260 \\
2260 \\
2660 \\
2660 \\
3250 \\
3250 \\
3770 \\
3770 \\
3250 \\
3250 \\
2664 \\
2664 \\
2294 \\
2260\end{array}$ & $\begin{array}{l}12.00 \\
12.00 \\
12.00 \\
12.00 \\
12.00 \\
12.00 \\
12.00 \\
12.00 \\
12.00 \\
12.00 \\
12.00 \\
12.00 \\
12.00 \\
12.00 \\
13.36 \\
12.00\end{array}$ & $\begin{array}{r}12.19 \\
12.31 \\
9.97 \\
8.72 \\
7.79 \\
7.18 \\
6.82 \\
6.92 \\
6.78 \\
6.84 \\
7.40 \\
7.48 \\
8.68 \\
9.02 \\
10.48 \\
10.42\end{array}$ & $\begin{array}{l}1.39 \\
1.38 \\
1.50 \\
1.66 \\
1.73 \\
2.00 \\
1.63 \\
1.76 \\
2.13 \\
1.99 \\
2.02 \\
1.63 \\
1.63 \\
1.55 \\
1.39 \\
1.46\end{array}$ & $\begin{array}{r}13.58 \\
13.69 \\
11.47 \\
10.38 \\
9.52 \\
9.18 \\
8.45 \\
8.68 \\
8.91 \\
8.83 \\
9.42 \\
9.11 \\
10.31 \\
10.57 \\
11.87 \\
11.88\end{array}$ & $\begin{array}{r}-1.58 \\
-1.68 \\
+0.53 \\
+1.62 \\
+2.48 \\
+2.82 \\
+3.55 \\
+3.32 \\
+3.09 \\
+3.17 \\
+2.58 \\
+2.89 \\
+1.69 \\
+1.43 \\
+1.49 \\
+0.12\end{array}$ & $\begin{array}{l}-1.63 \\
+1.08 \\
+2.65 \\
+3.44 \\
+3.13 \\
+2.74 \\
+1.51\end{array}$ & $\begin{array}{l}2.00 \\
1.59 \\
1.31 \\
1.22 \\
1.22 \\
1.21 \\
1.26 \\
1.40 \\
1.40 \\
1.70 \\
1.45 \\
1.28 \\
1.26 \\
1.00 \\
1.06 \\
1.30\end{array}$ & $\begin{array}{r}-0.58 \\
-0.23 \\
+0.18 \\
+0.19 \\
+0.44 \\
+0.40 \\
+0.63 \\
+0.07 \\
+0.39 \\
+0.98 \\
+0.08 \\
+0.04 \\
-0.10 \\
-0.50 \\
-0.10 \\
+0.10\end{array}$ & $\begin{array}{l}29 \\
30 \\
36 \\
24 \\
20 \\
18 \\
\\
16 \\
18 \\
16 \\
23 \\
24 \\
22 \\
\\
20\end{array}$ & $\begin{array}{l}2.27 \\
2.14 \\
2.19 \\
2.62 \\
2.51 \\
2.72 \\
2.68 \\
2.87 \\
2.91 \\
3.11 \\
2.76 \\
2.80 \\
3.12 \\
3.03 \\
3.06 \\
3.08\end{array}$ & $\begin{array}{l}3.96 \\
4.20 \\
4.45 \\
4.91 \\
4.75 \\
4.94 \\
4.90 \\
5.08 \\
5.20 \\
5.33 \\
4.66 \\
4.93 \\
5.19 \\
5.28 \\
5.11 \\
5.14\end{array}$ \\
\hline
\end{tabular}


creased by subsequent caloric additions as his nitrogen hunger, so to speak, was gradually satisfied. With nitrogen stores relatively replete in the latter part of the study, a caloric intake less than 2591 , or 88 per kgm., did not insure a maximum nitrogen balance. Such a high caloric diet, however, could not be maintained for a long time. For that reason only 2310 calories were given subsequently, when the effects of protein intake were studied, and this level of caloric intake was considered the optimum. the amount of urinary protein nitrogen did not vary regularly or significantly, although it showed a perceptible tendency to decrease with improvement of the patient's general condition.

In the first patient plasma albumin remained approximately at 3.7 per cent and total protein at 5.9 per cent, values above the lower limits of normal. In the second patient there was a steady increase in albumin as well as in total protein as the caloric level of the diet was raised, although subsequent lowering of the caloric intake failed

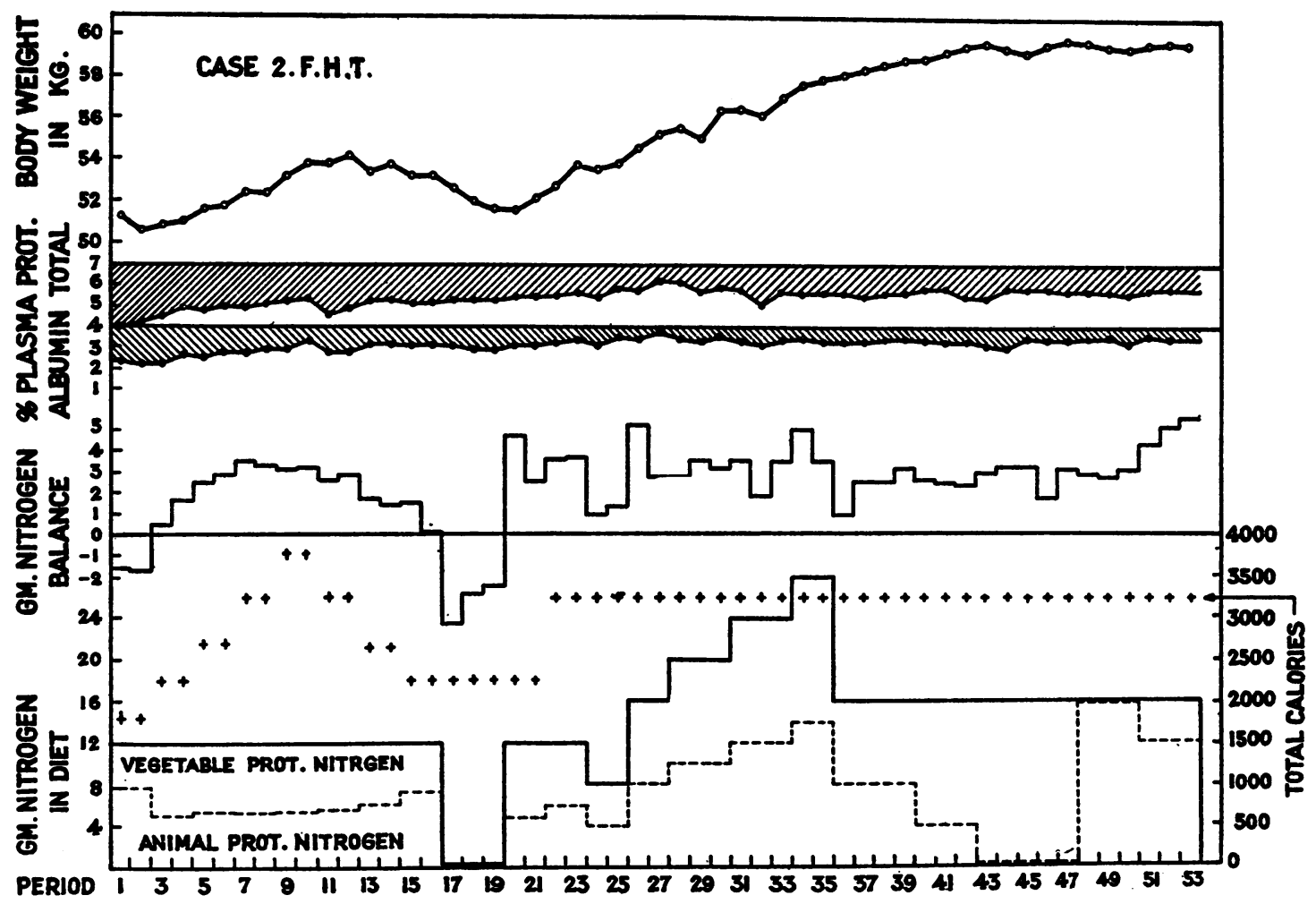

Fig. 2. Case 2. Nitrogen Balance, Plasma Proteins, and Body Weight on Diets with Varying Total Calories, Protein Intake, and Proportion of Animal and Vegetable Protein.

Both patients gained weight with higher caloric diets. As the first patient had no edema, and the second patient showed at the beginning of the study only slight pitting edema over the tibiae which disappeared completely a little later, it is assumed that the weight gained represented body tissue. The tendency to gain weight, like the positive nitrogen balance, became less as time went on, so that a higher caloric intake was necessary to bring about a gain in weight in the latter part of the experiment than in the first studies.

In Case 2, in which albuminuria was present, to bring about a reverse change in protein concentration. The plasma albumin rose from 2.27 to 3.08 per cent and total protein from 3.96 to 5.14 per cent within the period of two months' study corresponding to the transition from slight pitting edema to complete disappearance of edema, a point of interest in connection with the pathogenesis of nephrotic edema.

\section{Effect of different levels of protein intake}

With a constant caloric intake, the degree of nitrogen gain can be increased by raising the 
TABLE V

Case 1. Effect of different levels of protein intake. Calories 2310. Animal protein 50 per cent

\begin{tabular}{|c|c|c|c|c|c|c|c|c|c|c|c|}
\hline \multirow{2}{*}{$\begin{array}{c}\text { Period } \\
\text { number }\end{array}$} & \multirow{2}{*}{ Protein } & \multicolumn{6}{|c|}{ Average daily nitrogen metabolism } & \multirow{2}{*}{$\begin{array}{c}\text { Body } \\
\text { weight } \\
\text { change }\end{array}$} & \multicolumn{3}{|c|}{ Plasma } \\
\hline & & Intake & Urine & Stool & Total & Balance & Average & & $\begin{array}{c}\text { Nonprotein } \\
\text { nitrogen }\end{array}$ & Albumin & $\underset{\text { protein }}{\text { Total }}$ \\
\hline & grams & grams & grams & grams & grams & grams & grams & kgm. & $\begin{array}{l}\text { mgm. per } \\
100 \text { cc. }\end{array}$ & $\begin{array}{l}\text { grams per } \\
100 \text { cc. }\end{array}$ & $\begin{array}{l}\text { grams per } \\
100 \text { cc. }\end{array}$ \\
\hline $\begin{array}{l}22 \\
23 \\
24 \\
25 \\
26 \\
27 \\
28 \\
29 \\
30 \\
31 \\
32\end{array}$ & $\begin{array}{r}50 \\
50 \\
75 \\
75 \\
75 \\
100 \\
100 \\
100 \\
125 \\
125 \\
125\end{array}$ & $\begin{array}{r}8.00 \\
8.00 \\
12.00 \\
12.00 \\
12.00 \\
16.00 \\
16.00 \\
16.00 \\
20.00 \\
20.00 \\
20.00\end{array}$ & $\begin{array}{r}5.35 \\
4.02 \\
6.45 \\
7.50 \\
8.21 \\
10.96 \\
13.28 \\
12.75 \\
15.01 \\
15.15 \\
15.48\end{array}$ & $\begin{array}{l}1.32 \\
1.60 \\
1.57 \\
1.53 \\
1.40 \\
1.72 \\
0.74 \\
1.51 \\
1.99 \\
2.02 \\
2.11\end{array}$ & $\begin{array}{r}6.67 \\
5.62 \\
8.02 \\
9.03 \\
9.61 \\
12.68 \\
14.02 \\
14.26 \\
17.00 \\
17.17 \\
17.59\end{array}$ & $\begin{array}{r}+1.33 \\
+2.38 \\
+3.98 \\
+2.97 \\
+2.39 \\
+3.32 \\
+1.98 \\
+1.74 \\
+3.00 \\
+2.83 \\
+2.41\end{array}$ & $\begin{array}{l}+1.86 \\
+3.11 \\
+2.35 \\
+2.75\end{array}$ & $\begin{array}{r}+0.43 \\
+0.19 \\
+0.14 \\
+0.36 \\
+0.25 \\
-0.26 \\
-0.03 \\
+0.14 \\
+0.29 \\
+0.11 \\
+0.26\end{array}$ & $\begin{array}{l}17 \\
24 \\
24 \\
23 \\
19 \\
25 \\
25 \\
27 \\
17 \\
21 \\
24\end{array}$ & $\begin{array}{l}3.86 \\
3.65 \\
3.72 \\
3.68 \\
3.74 \\
3.57 \\
3.78 \\
3.90 \\
3.82 \\
4.01 \\
4.11\end{array}$ & $\begin{array}{l}5.78 \\
5.83 \\
6.10 \\
6.13 \\
6.12 \\
6.18 \\
6.09 \\
6.25 \\
6.01 \\
6.27 \\
6.44\end{array}$ \\
\hline
\end{tabular}

level of protein feeding to a certain extent, beyond which further increase in protein intake no longer improves the nitrogen balance, even if patients can tolerate the high protein diet.

In Case 1 (Table V), with a constant intake of 2310 calories, a maximum nitrogen retention of 3.11 grams daily was reached, the diet containing 75 grams of protein, or 2.5 grams per $\mathrm{kgm}$. In Case 2 (Table VI), with a constant caloric in- take of 3250 , a maximum of 4.02 grams of nitrogen per day was retained when 100 grams of protein, or 1.8 gram per kgm., were fed. These amounts of protein correspond to 12 to 13 per cent of the total caloric intake. Further increase in protein failed to increase the nitrogen retention. In fact, nitrogen balances with protein intakes higher than 12 to 13 per cent were slightly lower, except during Periods 34 and 35 in Case 2, in

TABLE VI

Case 2. Effect of the variations in protein intake.

Calories: 2270 for Periods 17 to 21 and 3260 for Periods 22 to 35 . Animal protein: none for Periods 17 to 19,40 per cent for Periods 20 and 21 , and 50 per cent for the remaining periods

\begin{tabular}{|c|c|c|c|c|c|c|c|c|c|c|c|c|}
\hline \multirow[b]{2}{*}{$\begin{array}{c}\text { Period } \\
\text { number }\end{array}$} & \multirow[b]{2}{*}{ Protein } & \multicolumn{7}{|c|}{ Average daily nitrogen metabolism } & \multirow{2}{*}{$\begin{array}{c}\text { Body } \\
\text { weight } \\
\text { change }\end{array}$} & \multicolumn{3}{|c|}{ Plasma } \\
\hline & & Intake & Urine & Stool & Total & Balance & $\begin{array}{l}\text { Average } \\
\text { balance }\end{array}$ & $\begin{array}{c}\text { Urine } \\
\text { protein } \\
\text { nitrogen }\end{array}$ & & $\begin{array}{c}\text { Nonprotein } \\
\text { nitrogen }\end{array}$ & Albumin & $\begin{array}{c}\text { Total } \\
\text { protein }\end{array}$ \\
\hline & grams & grams & grams & grams & grams & grams & grams & grams & kgm. & $\begin{array}{l}\text { mgm. per } \\
100 \text { cc. }\end{array}$ & $\begin{array}{l}\text { grams per } \\
100 \text { cc. }\end{array}$ & $\begin{array}{l}\text { grams per } \\
100 \text { cc. }\end{array}$ \\
\hline $\begin{array}{l}17 \\
18 \\
19 \\
20 \\
21 \\
22 \\
23 \\
24 \\
25 \\
26 \\
27 \\
28 \\
29 \\
30 \\
31 \\
32 \\
33 \\
34 \\
35\end{array}$ & $\begin{array}{r}2 \\
2 \\
2 \\
75 \\
75 \\
75 \\
75 \\
50 \\
50 \\
100 \\
100 \\
125 \\
125 \\
125 \\
150 \\
150 \\
150 \\
175 \\
175\end{array}$ & $\begin{array}{r}0.33 \\
0.37 \\
0.37 \\
12.00 \\
12.00 \\
12.00 \\
12.00 \\
8.00 \\
8.00 \\
16.00 \\
16.00 \\
19.02 \\
20.00 \\
20.00 \\
24.00 \\
24.00 \\
24.00 \\
27.80 \\
25.18\end{array}$ & $\begin{array}{r}3.79 \\
2.56 \\
2.19 \\
6.01 \\
7.56 \\
6.41 \\
6.44 \\
5.43 \\
4.98 \\
8.63 \\
10.88 \\
13.50 \\
14.16 \\
14.48 \\
17.48 \\
19.13 \\
17.72 \\
19.51 \\
18.54\end{array}$ & $\begin{array}{l}0.82 \\
0.66 \\
0.64 \\
1.25 \\
1.91 \\
1.94 \\
1.82 \\
1.60 \\
1.64 \\
2.11 \\
2.33 \\
2.71 \\
2.26 \\
2.34 \\
2.97 \\
3.01 \\
2.78 \\
3.24 \\
3.08\end{array}$ & $\begin{array}{r}4.61 \\
3.22 \\
2.83 \\
7.26 \\
9.47 \\
8.35 \\
8.26 \\
7.03 \\
6.62 \\
10.74 \\
13.21 \\
16.21 \\
16.42 \\
16.82 \\
20.45 \\
22.14 \\
20.50 \\
22.75 \\
21.62\end{array}$ & $\begin{array}{l}-4.28 \\
-2.85 \\
-2.46 \\
+4.73 \\
+2.53 \\
+3.65 \\
+3.74 \\
+0.97 \\
+1.38 \\
+5.26 \\
+2.79 \\
+2.81 \\
+3.58 \\
+3.18 \\
+3.55 \\
+1.86 \\
+3.50 \\
+5.05 \\
+3.56\end{array}$ & $\begin{array}{l}+1.18 \\
+4.02 \\
+3.19 \\
+2.97 \\
+4.30\end{array}$ & $\begin{array}{l}0.81 \\
0.58 \\
0.49 \\
0.57 \\
0.68 \\
0.66 \\
0.59 \\
0.51 \\
0.58 \\
0.50 \\
0.39 \\
0.51 \\
0.50 \\
0.76 \\
0.69 \\
0.75 \\
0.73 \\
0.59 \\
0.42\end{array}$ & $\begin{array}{l}-0.70 \\
-0.91 \\
-0.14 \\
+0.13 \\
+0.19 \\
+1.34 \\
+0.61 \\
-0.98 \\
+0.96 \\
+0.90 \\
+0.44 \\
+0.15 \\
+0.71 \\
+0.40 \\
+0.16 \\
+0.34 \\
+0.32 \\
+0.54 \\
+0.04\end{array}$ & $\begin{array}{l}17 \\
16 \\
16 \\
30 \\
27 \\
24 \\
20 \\
18 \\
19 \\
29 \\
29 \\
30 \\
32 \\
32 \\
29 \\
32 \\
\\
35 \\
36\end{array}$ & $\begin{array}{l}3.07 \\
2.96 \\
2.89 \\
3.06 \\
3.03 \\
3.21 \\
3.28 \\
3.05 \\
3.43 \\
3.45 \\
3.70 \\
3.44 \\
3.32 \\
3.49 \\
3.35 \\
3.11 \\
3.33 \\
3.39 \\
3.24\end{array}$ & $\begin{array}{l}\mathbf{5 . 2 7} \\
\mathbf{5 . 3 4} \\
\mathbf{5 . 3 5} \\
\mathbf{5 . 4 1} \\
\mathbf{5 . 4 3} \\
\mathbf{5 . 4 4} \\
\mathbf{5 . 6 2} \\
\mathbf{5 . 3 8} \\
\mathbf{5 . 7 8} \\
\mathbf{5 . 7 7} \\
\mathbf{6 . 2 2} \\
\mathbf{6 . 1 1} \\
\mathbf{5 . 6 8} \\
\mathbf{5 . 9 4} \\
\mathbf{5 . 7 7} \\
\mathbf{5 . 0 6} \\
\mathbf{5 . 7 0} \\
\mathbf{5 . 6 1} \\
\mathbf{5 . 3 9}\end{array}$ \\
\hline
\end{tabular}


which protein feeding to the level of 21.4 per cent caused a nitrogen gain of 4.30 grams per day. However, such a high level of protein intake was not tolerated by the patient for more than a few days.

It is to be noted that the first patient required more protein, as well as more calories per $\mathrm{kgm}$., than the second patient, to produce a maximum nitrogen retention. This may be referable to the age of the first patient, which was only 13 , a time when active growth goes on. In the case of nephrosis in a child of six reported by Cowie et al. (19), a satisfactory nitrogen gain was attained by feeding 88 calories and 3.8 grams of protein per kgm.

Case 2 afforded an opportunity to observe the effects of an almost protein-free diet. This was given for 12 days (Periods 17, 18, and 19). There was a marked negative nitrogen balance with loss of body weight. However, nitrogen loss tended to diminish so that only 2.46 grams of nitrogen were lost daily during the last period. The average nitrogen excretion amounted to 2.83 grams per day. When stool and urinary protein nitrogen are subtracted from the total excretion, the urinary nonprotein nitrogen amounts to 1.70 gram. This figure represents 0.033 gram of nitrogen per kgm. of body weight, a nitrogen minimum that is comparable with the results obtained in normal individuals (20). The two following periods (20 and 21) with the same caloric intake, but with 75 grams of protein, were intended to make up the nitrogen loss of the preceding periods on a "nitrogen-free" diet, preliminary to the studies of the effect of different levels of protein intake, reported above. Incidentally, the results of these two periods demonstrate the great avidity with which nitrogen is retained after periods of nitrogen depletion. The nitrogen gain during these two periods is the same as that in the next two periods (22 and 23) in which the energy of the diet was increased by approximately 1000 calories and is much better than the results of $\mathrm{Pe}$ riods 3 and 4 (Table IV) with the same caloric and protein intake.

In Case 2, the proteinuria did not change significantly with the changes in the level of dietary protein.

Plasma proteins tended to increase slightly with progressive increases of protein intake in Case 1, but did not change significantly in Case 2 when various levels of protein were fed. Plasma nonprotein nitrogen remained fairly constant throughout in Case 1, but to some extent varied directly with the level of protein feeding in Case 2.

\section{Comparison between animal and vegetable protein}

In Case 1 (Table VII) comparison of the effect on nitrogen balance of varying the proportions of animal and vegetable protein was made at two different times with different levels of protein and caloric intake. In Periods 1 to 4 , with protein at 25 grams and calories at 1750, the nitrogen balance obtained with animal protein was decidedly superior to that with vegetable protein. During Periods 33 to 47 , with protein at 75 grams and calories at 2310 , variations in the percentage of animal protein between 0 and 99 per cent resulted in slight changes in nitrogen balance. There was a small increase of nitrogen retention when the proportion of animal protein was progressively raised. In Case 2 (Table VIII) no clear-cut differences in nitrogen balance attended variation of the proportion of animal protein, although the nitrogen gain was greater during the three periods ( 51 to 53 ) on 75 per cent of animal protein than in any other periods. When optimum protein and caloric intake was maintained, the relative proportions of animal and vegetable protein in the diet did not seem to have much influence on nitrogen retention.

The albuminuria in Case 2 again showed no marked variation, although a tendency to decrease was discernible during the course of study.

No marked variations were observed in either case in plasma protein or nonprotein nitrogen when the proportions of animal and vegetable protein were varied.

\section{SUMMARY AND CONCLUSIONS}

1. In two patients with the nephrotic type of Bright's disease, one aged 13 and the other aged 35 , nitrogen balances and plasma proteins were studied in relation to diets in which total calories, protein content, and percentage of animal and vegetable protein were varied.

2 . With a moderate protein intake, nitrogen retention could be progressively increased by the addition of calories in the form of carbohydrate 
and fat. The first patient showed a maximum nitrogen gain at 88 calories per kgm., and the second patient retained the greatest amount of nitrogen at 62 calories per kgm. Further increase in caloric intake resulted in no increases in the nitrogen retained.
3. When these patients were fed the optimum number of calories, raising the protein intake increased the nitrogen retention somewhat. The maximum nitrogen retention was reached when 75 grams of protein were fed in Case 1 and with 100 grams in Case 2. These amounts correspond

TABLE VII

Case 1. Effect of different proportions of animal and vegetable protein.

Calories 1750 and protein 25 grams for Periods 1 to 4 . Calories 2310 and proteins 75 grams for Periods 33 to 47

\begin{tabular}{|c|c|c|c|c|c|c|c|c|c|c|c|}
\hline \multirow{2}{*}{$\begin{array}{c}\text { Period } \\
\text { number }\end{array}$} & \multirow{2}{*}{$\begin{array}{l}\text { Animal } \\
\text { protein }\end{array}$} & \multicolumn{6}{|c|}{ Average daily nitrogen metabolism } & \multirow{2}{*}{$\begin{array}{c}\text { Body } \\
\text { weight } \\
\text { change }\end{array}$} & \multicolumn{3}{|c|}{ Plasma } \\
\hline & & Intake & Urine & Stool & Total & Balance & Average & & $\begin{array}{c}\text { Nonprotein } \\
\text { nitrogen }\end{array}$ & Albumin & $\begin{array}{c}\text { Total } \\
\text { protein }\end{array}$ \\
\hline & per cent & grams & grams & grams & grams & grams & grams & kgm. & $\begin{array}{l}\text { mgm. per } \\
100 \text { cc. }\end{array}$ & $\begin{array}{c}\text { grams per } \\
100 \text { cc. }\end{array}$ & $\begin{array}{l}\text { grams per } \\
100 \text { cc. }\end{array}$ \\
\hline $\begin{array}{r}1 \\
2 \\
3 \\
4 \\
33 \\
34 \\
35 \\
36 \\
37 \\
38 \\
39 \\
40 \\
41 \\
42 \\
43 \\
44 \\
45 \\
46 \\
47\end{array}$ & $\begin{array}{r}0 \\
0 \\
92 \\
92 \\
50 \\
50 \\
50 \\
25 \\
25 \\
25 \\
0 \\
0 \\
0 \\
0 \\
99 \\
99 \\
99 \\
75 \\
75\end{array}$ & $\begin{array}{r}3.95 \\
3.95 \\
4.04 \\
4.04 \\
11.97 \\
11.97 \\
11.97 \\
12.03 \\
12.03 \\
12.03 \\
11.97 \\
11.97 \\
11.97 \\
11.97 \\
12.08 \\
12.08 \\
12.08 \\
12.02 \\
12.02\end{array}$ & $\begin{array}{l}2.13 \\
2.20 \\
1.78 \\
1.91 \\
9.72 \\
8.76 \\
8.72 \\
8.21 \\
8.75 \\
8.38 \\
7.54 \\
7.77 \\
7.80 \\
8.44 \\
8.40 \\
8.84 \\
7.97 \\
8.12 \\
9.04\end{array}$ & $\begin{array}{l}1.27 \\
0.87 \\
0.55 \\
0.90 \\
1.15 \\
1.15 \\
0.82 \\
2.20 \\
1.54 \\
1.86 \\
2.52 \\
2.35 \\
2.25 \\
2.90 \\
1.08 \\
0.92 \\
0.82 \\
0.94 \\
0.97\end{array}$ & $\begin{array}{r}3.40 \\
3.07 \\
2.33 \\
2.81 \\
10.87 \\
9.91 \\
9.54 \\
10.41 \\
10.29 \\
10.24 \\
10.06 \\
10.12 \\
10.05 \\
11.34 \\
9.48 \\
9.76 \\
8.79 \\
9.06 \\
10.01\end{array}$ & $\begin{array}{l}+0.55 \\
+0.88 \\
+1.71 \\
+1.23 \\
+1.10 \\
+2.06 \\
+2.43 \\
+1.62 \\
+1.74 \\
+1.79 \\
+1.91 \\
+1.85 \\
+1.92 \\
+0.63 \\
+2.60 \\
+2.32 \\
+3.29 \\
+2.96 \\
+2.01\end{array}$ & $\begin{array}{l}+0.72 \\
+1.47 \\
+1.86 \\
+1.72 \\
+1.58 \\
+2.74 \\
+2.48\end{array}$ & $\begin{array}{l}+0.31 \\
-0.06 \\
+0.40 \\
+0.10 \\
-0.09 \\
+0.02 \\
+0.11 \\
+0.25 \\
-0.05 \\
+0.39 \\
-0.07 \\
-0.01 \\
+0.23\end{array}$ & $\begin{array}{l}15 \\
15 \\
19 \\
30 \\
18 \\
20 \\
21 \\
21 \\
19 \\
19 \\
20 \\
22 \\
19 \\
20 \\
21 \\
20 \\
22\end{array}$ & $\begin{array}{l}3.12 \\
3.26 \\
3.54 \\
3.74 \\
3.65 \\
3.60 \\
3.55 \\
3.51 \\
3.85 \\
3.73 \\
3.67 \\
3.73 \\
3.67 \\
3.77 \\
3.62 \\
3.60 \\
3.54 \\
3.40 \\
3.71\end{array}$ & $\begin{array}{l}\mathbf{5 . 6 1} \\
\mathbf{5 . 6 4} \\
\mathbf{5 . 5 1} \\
\mathbf{5 . 9 9} \\
\mathbf{5 . 9 4} \\
\mathbf{5 . 9 4} \\
\mathbf{5 . 9 6} \\
\mathbf{5 . 8 4} \\
\mathbf{5 . 8 7} \\
\mathbf{5 . 7 8} \\
\mathbf{5 . 4 9} \\
\mathbf{5 . 7 2} \\
\mathbf{5 . 9 7} \\
\mathbf{5 . 7 0} \\
\mathbf{5 . 8 1} \\
\mathbf{5 . 6 2} \\
\mathbf{5 . 7 7} \\
\mathbf{5 . 7 2} \\
\mathbf{5 . 7 6}\end{array}$ \\
\hline
\end{tabular}

TABLE VIII

Case 2. Variations in percentage of animal and vegetable proteins. Calories 3260. Protein 100 grams

\begin{tabular}{|c|c|c|c|c|c|c|c|c|c|c|c|c|}
\hline \multirow{2}{*}{$\begin{array}{c}\text { Period } \\
\text { number }\end{array}$} & \multirow{2}{*}{$\begin{array}{l}\text { Animal } \\
\text { protein }\end{array}$} & \multicolumn{7}{|c|}{ Average daily nitrogen metabolism } & \multirow{2}{*}{$\begin{array}{c}\text { Body } \\
\text { weight } \\
\text { change }\end{array}$} & \multicolumn{3}{|c|}{ Plasma } \\
\hline & & Intake & Urine & Stool & Total & Balance & Average & $\begin{array}{c}\text { Urine } \\
\text { protein } \\
\mathrm{N}_{2}\end{array}$ & & $\begin{array}{l}\text { Nonprotein } \\
\text { nitrogen }\end{array}$ & Albumin & $\begin{array}{c}\text { Total } \\
\text { protein }\end{array}$ \\
\hline $\begin{array}{l}36 \\
37 \\
38 \\
39 \\
40 \\
41 \\
42 \\
43 \\
44 \\
45 \\
46 \\
47 \\
48 \\
49 \\
\mathbf{5 0} \\
\mathbf{5 1} \\
\mathbf{5 2} \\
\mathbf{5 3}\end{array}$ & $\begin{array}{c}\text { per cent } \\
50 \\
50 \\
50 \\
50 \\
25 \\
25 \\
25 \\
0 \\
0 \\
0 \\
0 \\
0 \\
98 \\
98 \\
98 \\
75 \\
75 \\
75\end{array}$ & $\begin{array}{l}\text { grams } \\
15.96 \\
15.96 \\
15.96 \\
15.96 \\
15.98 \\
15.98 \\
15.98 \\
15.97 \\
15.97 \\
15.97 \\
15.97 \\
15.97 \\
16.02 \\
16.02 \\
16.02 \\
15.94 \\
15.94 \\
15.94\end{array}$ & $\begin{array}{l}\text { grams } \\
13.20 \\
11.88 \\
11.32 \\
11.02 \\
11.20 \\
11.46 \\
11.64 \\
10.98 \\
10.63 \\
10.72 \\
12.11 \\
10.66 \\
11.94 \\
12.37 \\
11.98 \\
10.18 \\
9.75 \\
8.88\end{array}$ & $\begin{array}{l}\text { grams } \\
1.82 \\
1.51 \\
2.06 \\
1.72 \\
2.14 \\
2.04 \\
1.90 \\
2.05 \\
2.09 \\
2.01 \\
2.05 \\
2.19 \\
1.18 \\
0.88 \\
0.91 \\
1.37 \\
0.99 \\
1.46\end{array}$ & $\begin{array}{l}\text { grams } \\
15.02 \\
13.39 \\
13.38 \\
12.74 \\
13.34 \\
13.50 \\
13.54 \\
13.03 \\
12.72 \\
12.73 \\
14.16 \\
12.85 \\
13.12 \\
13.25 \\
12.89 \\
11.55 \\
10.74 \\
10.34\end{array}$ & $\begin{array}{c}\text { grams } \\
+0.94 \\
+2.57 \\
+2.58 \\
+3.22 \\
+2.64 \\
+2.48 \\
+2.44 \\
+2.95 \\
+3.25 \\
+3.25 \\
+1.81 \\
+3.12 \\
+2.90 \\
+2.77 \\
+3.13 \\
+4.39 \\
+5.20 \\
+5.60\end{array}$ & $\begin{array}{l}+2.33 \\
+2.52 \\
+2.88\end{array}$ & $\begin{array}{l}\text { grams } \\
0.76 \\
0.63 \\
0.72 \\
0.56 \\
0.53 \\
0.16 \\
0.29 \\
0.63 \\
0.34 \\
0.51 \\
0.57 \\
0.31 \\
0.41 \\
0.38 \\
0.30 \\
0.24 \\
0.18 \\
0.18\end{array}$ & $\begin{array}{c}\text { kgm. } \\
+0.55 \\
-0.16 \\
+0.68 \\
+0.08 \\
+0.23 \\
+0.17 \\
-0.06 \\
+0.36 \\
-0.20 \\
-0.22 \\
+0.56 \\
+0.23 \\
-0.10 \\
-0.18 \\
-0.01 \\
+0.52 \\
-0.29 \\
-0.37\end{array}$ & $\begin{array}{c}\text { mgm. per } \\
100 \text { cc. } \\
25 \\
\\
26 \\
31 \\
27 \\
28 \\
30 \\
30 \\
26 \\
24 \\
25 \\
27 \\
30 \\
30 \\
30 \\
24 \\
29\end{array}$ & $\begin{array}{c}\text { grams per } \\
100 \text { cc. } \\
3.27 \\
3.41 \\
3.28 \\
3.36 \\
3.42 \\
3.32 \\
3.27 \\
3.25 \\
3.09 \\
3.48 \\
3.42 \\
3.39 \\
3.48 \\
3.46 \\
3.13 \\
3.48 \\
3.38\end{array}$ & $\begin{array}{c}\text { grams per } \\
100 \text { cc. } \\
\mathbf{5 . 6 5} \\
\mathbf{5 . 5 9} \\
\mathbf{5 . 4 1} \\
\mathbf{5 . 6 1} \\
\mathbf{5 . 5 9} \\
\mathbf{5 . 8 7} \\
\mathbf{5 . 8 6} \\
\mathbf{5 . 4 2} \\
\mathbf{5 . 4 0} \\
\mathbf{5 . 8 6} \\
\mathbf{5 . 8 6} \\
\mathbf{5 . 7 9} \\
\mathbf{5 . 7 2} \\
\mathbf{5 . 7 2} \\
\mathbf{5 . 5 2} \\
\mathbf{5 . 8 2} \\
\mathbf{5 . 7 8}\end{array}$ \\
\hline
\end{tabular}


to 2.5 grams and 1.8 gram per $\mathrm{kgm}$. of body weight and constitute 12 to 13 per cent of the total calories. Feeding more protein did not increase the positive nitrogen balance.

4. The first patient showed a slightly increasing nitrogen retention as higher percentages of animal protein were fed, while in the second patient the nature of protein made no distinct difference. While it is impractical to feed a purely animal protein diet, a diet with at least 50 per cent of its protein of animal origin would seem to insure the best nitrogen gain.

5. Changes in plasma proteins were slow, even in the presence of marked nitrogen retention. The proteins remained at about the same level throughout Case 1 . In Case 2 they slowly increased during the early part of the study.

6. In the second patient, in whom albuminuria decreased as the study progressed, there was no significant change in the albuminuria related to the level of protein intake.

\section{BIBLIOGRAPHY}

1. Moore, N. S., and Van Slyke, D. D., The relationships between plasma specific gravity, plasma protein content, and edema in nephritis. J. Clin. Invest., 1930, 8, 337.

2. Leiter, L., Experimental nephrotic edema. Arch. Int. Med., 1931, 48, 1.

3. Barker, M. H., and Kirk, E. J., Experimental edema (nephrosis) in dogs in relation to edema of renal origin in patients. Arch. Int. Med., 1930, 45, 319.

4. Bruckman, F. S., D'Esopo, L. M., and Peters, J. P., The plasma proteins in relation to blood hydration. IV. Malnutrition and the serum proteins. J. Clin. Invest., 1930, 8, 577.

5. Bruckman, F. S., and Peters, J. P., The plasma proteins in relation to blood hydration. V. Serum proteins and malnutritional or cachectic edema. J. Clin. Invest., 1930, 8, 591.
6. Ling, S. M., Changes of serum proteins in undernutrition. Chinese J. Physiol., 1931, 5, 1.

7. Liu, S. H., Chu, H. I., Wang, S. H., and Chung, H. L., Nutritional edema. I. The effects of the level and quality of protein intake on nitrogen balance, plasma proteins and edema. Chinese J. Physiol., 1932, 6, 73.

8. Epstein, A. A., Concerning the causation of edema in chronic parenchymatous nephritis; method for its alleviation. Am. J. M. Sc., 1917, 154, 638.

9. Epstein, A. A., Further observations on the nature and treatment of chronic nephrosis. Am. J. M. Sc., 1922, 163, 167.

10. Kollert, V., Uber das Wesen der Nephrosen. Ztschr. f. klin. Med., 1923, 97, 287.

11. Peters, J. P., Bulger, H. A., Lee, C., and Murphy, C. F., The relation of albuminuria to protein requirement in nephritis. Arch. Int. Med., 1926, 37, 153.

12. MacLean, H., Modern Methods in the Diagnosis and Treatment of Renal Disease. Constable and Co., London, 1924, 2d ed.

13. Worley, E., The effect of high protein diet on albuminuria and blood urea in cases of nephritis. Quart. J. Med., 1920, 14, 88.

14. Linder, G. C., Lundsgaard, C., and Van Slyke, D. D., The concentration of the plasma proteins in nephritis. J. Exper. Med., 1924, 39, 887.

15. Wu, $\mathrm{H}$., Nutritive value of Chinese foods. Chinese J. Physiol., (rep. ser.) no. 1, 1928, p. 153.

16. Folin, O., and Wright, L. E., A simplified macroKjeldahl method for urine. J. Biol. Chem., 1919, 38, 461.

17. Howe, P. E., The determination of proteins in blood -A micro method. J. Biol. Chem., 1921, 49, 109.

18. Van Slyke, D. D., Gasometric micro-Kjeldahl determination of nitrogen. J. Biol. Chem., 1927, 71, 235.

19. Cowie, D. M., Jarvis, K. M., and Cooperstock, M., Metabolism studies in nephrosis with special reference to the relationship of protein intake to nitrogen retention, edema and albuminuria. Am. J. Dis. Child., 1930, 40, 465.

20. Deuel, H. J., Sandiford, I., Sandiford, K., and Boothby, W. M., A study of the nitrogen minimum. J. Biol. Chem., 1928, 76, 391. 